\title{
The Prevalence of Allergic Rhinitis and its Impact on Quality of Life Among Students of the Syrian Private University
}

Saeed A.Kadri ( $\sim$ saeedkadri1997@gmail.com )

Syrian Private University

Ezat Albakri

Syrian private University

Batoul Bakkar

Syrian Private University

Fatema Mohsen

Syrian Private University https://orcid.org/0000-0003-3472-6099

Louei Darjazini Nahas

Syrian Private University

\section{Research Article}

Keywords: Allergic rhinitis, Syria, mini rhinoconjunctivitis quality of life questionnaire

Posted Date: March 7th, 2022

DOI: https://doi.org/10.21203/rs.3.rs-1420022/v1

License: (9) This work is licensed under a Creative Commons Attribution 4.0 International License. Read Full License 


\section{Abstract}

\section{Background:}

Allergic rhinitis is one of the most common chronic respiratory diseases in the world. It has negative impacts, including complications, and comorbidities, all negatively impacting one's quality of life.

Aims: The current study aims to determine the prevalence of AR among students at Syrian Private University.

\section{Methods:}

A cross-sectional was conducted at the Syrian Private University. The survey included questions about demographics and two allergy-specific questionnaires, the mini rhinoconjunctivitis quality of life questionnaire and the activity impairment plus classroom impairment questionnaire. The mini rhinoconjunctivitis quality of life questionnaire was translated to Arabic language and then validated via Cronbach's alpha test.

\section{Results:}

Most participants were male 197(54\%), residents of Damascus/ Rural Damascus 321(87\%), and smokers $208(56 \%)$. Their ages ranged from 19-32 years, with a mean of $21.7( \pm 1.91)$ years. The prevalence of students diagnosed with AR was $115(31.1 \%)$. Total loss of academic attendance was $12.1 \%$, whereas the impairment of academic productivity was $21.8 \%$

\section{Conclusion:}

Almost a third of the sample has allergic rhinitis, and a fifth reported impaired academic productivity, consequently exerting burdens upon students' lives. Further studies are required to evaluate the causes and establish effective management plans.

\section{Introduction}

Allergic rhinitis (AR) is among the most common chronic respiratory diseases in the world. ${ }^{[1]}$ This condition affects $10 \%-40 \%$ of the population and continues to spread. ${ }^{[2]}$

Environmental exposure to allergens and genetic susceptibility to develop AR encompasses complex interactions.[3] Clinical features of AR usually present after exposure to an allergen. ${ }^{[4]}$ Symptoms of AR include nasal congestion, rhinorrhea, sneezing, itchy eyes, redness in the eye, and dacryorrhea. ${ }^{[5]}$ There are several triggers for AR, including animals, dust, mites, and cockroaches, pollen, smoke, and mold. ${ }^{[4]}$ AR can be categorized into seasonal or perennial, the first occurs during a particular season, while the latter occurs all year round. ${ }^{[6]}$ However, this classification was inconclusive, another classification was constructed to categorize AR according to its symptom duration as either intermittent (inflammation 
duration of $<6$ weeks) or persistent (symptoms throughout the year) and severity either mild (patients are broadly able to sleep normally and perform normal activities including work or school) or moderate/severe (significantly affect sleep and activities of daily living and/or if they are considered troublesome) ${ }^{[7]}$ The socio-economic burdens of AR have a significant impact on an individual's quality of life, sleep, school performance, and work productivity. ${ }^{[8]}$ Treatment options for AR comprise avoidance of allergens, and pharmacological treatment such as oral or nasal antihistamine, intranasal corticosteroids,

and allergen immunotherapy. ${ }^{[9]}$ Since exposure to polluted air was one of the reasons for exacerbation of AR symptoms, patients in Syria were suffering from this because of pollutants emitted from old diesel exhaust, as well as factories and laboratories that are built near residential areas. ${ }^{[10]}$ Additionally, war and harmful allergens have negatively affected the severity of AR symptoms.

The current study aims to determine the prevalence of AR among students at Syrian Private University (SPU). The objectives are to verify the use of the Arabic-language mini rhinoconjunctivitis quality of life questionnaire among students with AR and to assess the effect of allergies on the ability to work, attend classes, and perform routine daily activities.

\section{Methods}

\section{Study design, participants, and procedure:}

This cross-sectional study was conducted using a convenience sampling method during the start of the first semester (2021), at the Syrian Private University (SPU), Dara'a, Syria. All participants provided written consent for their participation. Students were informed their participation was voluntary, response to all questions was not mandatory, all of the responses were recorded anonymously, and were allowed to optout of the survey at any time. A structured self-completed Arabic-language questionnaire was distributed among students. The questionnaire contained 4 sections (54 questions): socio-demographic characteristics, mini rhinoconjunctivitis quality of life questionnaire (MiniRQLQ) (14 questions), allergic rhinitis and its impact on asthma (ARIA) (4 questions), and activity impairment questionnaire plus classroom impairment questions: allergy specific (Al+CIQ: AS) (5 questions).

\section{Ethical approval:}

Ethical approval was granted from the Institutional Review Board (IRB), Faculty of Medicine, Syrian Private University, Dara'a, Syria.

\section{Statistical analysis:}

Data were reported as frequencies and percentages (for categorical variables) or means, medians, and standard deviations (SD) (for continuous variables). Questionnaire reliability was studied by determining internal consistency using Cronbach's alpha test. A Cronbach's alpha value of $>0.70$ was predefined as satisfactory. ${ }^{[11]}$ 


\section{Results}

\section{Socio-demographics characteristics:}

Of 370 total students who completed the survey, 197(54\%) were male and 173(46\%) were female. Participants' ages ranged from 19-32 years, with a mean of $21.7( \pm 1.91)$ years. The majority of participants were residents of Damascus/ Rural Damascus 321(87\%). The prevalence of smoking was $208(56 \%), 76(36.5 \%)$ for the Hubble bubble, and $25(12.0 \%)$ for cigarettes. The sample was evenly distributed among the 6 faculties and the majority were in their third year 138(37.3\%) (Table 1). A family history of allergic conditions was reported among 71(61.7\%) students.

\section{Allergic Rhinitis its Impact on Asthma, and quality of life:}

The prevalence of students diagnosed with AR by a doctor was 115(31.1\%), 51(44.3\%) were male and 64(55.7\%) were female. AR's effect on the quality of life showed varying degrees of effect among students (table 2). AR and its impact on asthma were reported among students as mild and intermittent 64(83\%), mild and continuous 27(71), moderate/severe and intermittent 13(17\%), and moderate/severe and continuous $11(29 \%)$ (Table 2). The Arabic MiniRQLQ showed good internal consistency, with a Cronbach's alpha value of 0.93 .

\section{Activity Impairment and Classroom Impairment:}

Overall, the mean number of hours/week spent by our students in classes was $17.05( \pm 2.53)$. The mean Al + CIQ: AS score was 3.72( \pm 2.14$)$. Total loss of academic attendance was $12.1 \%$, whereas the impairment of academic productivity was $21.8 \%$ (Table 3 ).

\section{Discussion}

AR is a chronic respiratory disease that has severely affected mankinds' quality of life. This first study aims to reveal the prevalence of AR among students studying at the Syrian Private University $115(31.1 \%)$. In two studies conducted in Syria, the estimated prevalence of AR symptoms was $50.7 \%$ and $47.4 \%{ }^{[12,13]}$ Our prevalence was lower compared with Thailand 58.5\%, Saudi Arabia (44\%), and United Arab Emirates (32\%), but lower compared with South Korea (27\%), Canada (25\%), and Europe (21\%). ${ }^{[14-19]}$ A Syrian study conducted during the war screened for AR symptoms, the high prevalence of symptoms found among the population was attributed to the war, including exposure to various harmful substances, where they found a statistically significant correlation between AR and distress from war noises. ${ }^{[12]}$

With the increasing incidence of atopy worldwide, AR continues to impact health issues among the community, resulting in enormous consequences, including complications, and comorbidities causing significant burdens on one's quality of life. Therefore, it is paramount to assess the quality of life among students suffering from AR. Consequently, the Arabic-language mini rhinoconjunctivitis quality of life 
questionnaire was assessed for validity, a good internal consistency was found, Cronbach's alpha value of 0.93 .

The quality of life among students with AR showed varied responses across the scale. This was also the case in a Thailand study. ${ }^{[14]}$ The class impairment questionnaire revealed the total loss of academic attendance and impairment of academic productivity was $12.1 \%$ and $21.8 \%$ respectively. A study in Spain revealed the total loss of productivity was $21.2 \%$, whereas the impairment of daily activities was $22.0 \%$.

${ }^{[20]}$ Affected AR individuals may underperform in work or study settings, their job/ class-related relationships may be affected, and their professional careers may suffer. ${ }^{[20]}$

\section{Conclusion}

Our study revealed a high prevalence of AR among students at SPU. AR has negatively affected the students' quality of life. Further studies are required to evaluate the causes and establish effective management plans.

\section{Limitations:}

There are limitations in the study design and sampling method. Also, this study does not take into account students with AR, who are undiagnosed. A further study must be conducted to screen for those with undiagnosed AR. In addition, the quality of life, causes and triggers, and management plans regarding AR must be assessed on a national level.

\section{Abbreviations}

AR

Allergic Rhinitis

SPU

Syrian Private University

MiniRQLQ

Mini Rhinoconjunctivitis Quality of Life Questionnaire

ARIA

Allergic Rhinitis and its Impact on Asthma

$\mathrm{Al}+\mathrm{ClQ}$

AS:Activity Impairment Questionnaire plus Classroom Impairment Questions:Allergy Specific SD

Standard Deviation.

\section{Declarations}

\section{Acknowledgments:}


We are thankful to the management of the Syrian Private University and for their support in the field of medical training and research. We are thankful to everyone who participated in this study.

\section{Funding:}

This research received no specific grant from SPU or any other funding agency in the public, commercial or non-profit sectors.

\section{Availability of data and materials:}

All data related to this paper's conclusion are available and stored by the authors. All data are available from the corresponding author on a reasonable request.

\section{Ethics approval and consent to participate:}

This study was approved by the Institutional Review Board (IRB) at the Syrian Private University (SPU). All Participants confirmed their written consent by signing the consent form. Participation in the study was voluntary and participants were assured that anyone who was not inclined to participate or decided to withdraw after giving consent would not be victimized. All information collected from this study was kept strictly confidential.

\section{Consent for Publication:}

Not applicable.

\section{Competing interests:}

The authors declare that they have no competing interests.

\section{Authors' contributions:}

SA was responsible for study design, literature search, data analysis, and write-up; EA was responsible for study design and data collection; BB and FM participated in literature search and write-up; LN participated in the study design and reviewed the final draft. All authors read and approved the final draft.

\section{Abbreviations}

AR: Allergic Rhinitis; SPU: Syrian Private University; MiniRQLQ: Mini Rhinoconjunctivitis Quality of Life Questionnaire; ARIA: Allergic Rhinitis and its Impact on Asthma; Al+CIQ: AS: Activity Impairment Questionnaire plus Classroom Impairment Questions: Allergy Specific; SD: Standard Deviation. 


\section{References}

1. Dykewicz MS, Hamilos DL. Rhinitis and sinusitis. Journal of Allergy Clinical Immunology. 2010;125(2):S103-S15. doi: 10.1016/j.jaci.2009.12.989.

2. Brożek JL, Bousquet J, Agache I, Agarwal A, Bachert C, Bosnic-Anticevich S, et al. Allergic Rhinitis and its Impact on Asthma (ARIA) guidelines-2016 revision. Journal of Allergy Clinical Immunology. 2017;140(4):950-8. doi: 10.1016/j.jaci.2017.03.050.

3. Van Beijsterveldt C, Boomsma D. Genetics of parentally reported asthma, eczema and rhinitis in 5-yrold twins. European Respiratory Journal. 2007;29(3):516-21. doi: 10.1183/09031936.00065706.

4. Varshney J, Varshney H. Allergic rhinitis: an overview. Indian Journal of Otolaryngology and Head \& Neck Surgery. 2015;67(2):143-9. doi: 10.1007/s12070-015-0828-5.

5. Shedden A. Impact of nasal congestion on quality of life and work productivity in allergic rhinitis. Treatments in respiratory medicine. 2005;4(6):439-46. doi: 10.2165/00151829-200504060-00007.

6. Lee P, Mace S. An approach to allergic rhinitis. Allergy Rounds. 2009;1:1.

7. Leynaert B, Bousquet J, Neukirch C, Liard R, Neukirch F. Perennial rhinitis: an independent risk factor for asthma in nonatopic subjects: results from the European Community Respiratory Health Survey. Journal of Allergy Clinical Immunology. 1999;104(2):301-4. doi: 10.1016/S0091-6749(99)70370-2.

8. Greiner AN, Hellings PW, Rotiroti G, Scadding GK. Allergic rhinitis. The Lancet. 2011;378(9809):211222. doi: 10.1016/S0140-6736(11)60130-X.

9. Ivanova JI, Kelkar S, King S, Birnbaum HG, Hocker S, Phipps R, et al. Budget impact model of a 5grass sublingual immunotherapy tablet for the treatment of grass pollen-induced allergic rhinitis. Journal of medical economics. 2015;18(11):909-18. doi: 10.3111/13696998.2015.1061533.

10. Li CH, Sayeau K, Ellis AK. Air pollution and allergic rhinitis: role in symptom exacerbation and strategies for management. Journal of Asthma Allergy. 2020;13:285. doi: 10.2147/JAA.S237758.

11. Lohr KN. Assessing health status and quality-of-life instruments: attributes and review criteria. Quality of life Research. 2002;11(3):193-205. doi: 10.1023/A:1015291021312.

12. Kakaje A, Alhalabi MM, Alyousbashi A, Hamid A, Hosam Aldeen O. Allergic rhinitis and its epidemiological distribution in Syria: a high prevalence and additional risks in war time. BioMed Research International. 2020;2020. doi: 10.1155/2020/7212037.

13. Kakaje A, Alhalabi MM, Alyousbashi A, Ghareeb A. Allergic rhinitis, asthma and laryngopharyngeal reflux disease: a cross-sectional study on their reciprocal relations. Scientific Reports. 2021;11(1):18. doi: 10.1038/s41598-020-80793-1.

14. Sapsaprang S, Setabutr D, Kulalert P, Temboonnark P, Poachanukoon O. Evaluating the impact of allergic rhinitis on quality of life among Thai students. International Forum of Allergy \& Rhinology: Wiley Online Library; 2015. p. 801-7.

15. Yassin ${ }^{1}$ A, Maashi R, Zila A, Dilyh N, Dilyh S. Prevalence of allergic rhinitis among adults, Jazan Region, Saudi Arabia. 2017. 
16. Alsowaidi S, Abdulle A, Shehab A, Zuberbier T, Bernsen R. Allergic rhinitis: prevalence and possible risk factors in a Gulf Arab population. Allergy. 2010;65(2):208-12. doi: 10.1111/j.13989995.2009.02123.x.

17. An S-Y, Choi HG, Kim SW, Park B, Lee JS, Jang JH, et al. Analysis of various risk factors predisposing subjects to allergic rhinitis. Asian Pac J Allergy Immunol. 2015;33(2):143-51. doi: 10.12932/AP0554.33.2.2015

18. Hossenbaccus L, Linton S, Garvey S, Ellis AK. Towards definitive management of allergic rhinitis: best use of new and established therapies. Allergy, Asthma Clinical Immunology. 2020;16(1):1-17. doi: 10.1186/s13223-020-00436-y.

19. Janson C, Anto J, Burney P, Chinn S, De Marco R, Heinrich J. what are the main results so far? European Community Respiratory Health Survey II. European Respiratory Journal. 2001;18(3):598611. doi: 10.1183/09031936.01.00205801.

20. Roger A, Arcalá Campillo E, Torres M, Millan C, Jáuregui I, Mohedano E, et al. Reduced work/academic performance and quality of life in patients with allergic rhinitis and impact of allergen immunotherapy. Allergy, Asthma Clinical Immunology. 2016;12(1):1-9. doi: 10.1186/s13223-016-0146-9.

\section{Tables}

Table 1. Socio-demographic characteristics 
Table 1. Socio-demographic characteristics: $(N=370)$

$\begin{array}{lllll}\text { Gender (\%) } & \text { Male } & 197 & \text { Study year (\%) } & 1\end{array}$

Female

173

(46.7)

$10(2.7)$

2

90

(24.3)

Age $(\%) \quad<20$

3

40

138

(10.8)

(37.3)

20-24

308

(83.2)

75

(20.3)

25-29

5

21

(5.7)

43

(11.6)

30-34

6

$1(0.3)$

14 (3.8)

Medical

Condition (\%)

$\begin{array}{lll}\text { Yes } & 28 & \text { Smoking (\%) }\end{array}$

342

(92.4)

208

(56.2)

No

211

(57.0)

Smoking

method (\%)

162

(43.8)

\begin{tabular}{llll} 
Residence (\%) & Damascus & $\begin{array}{l}211 \\
(57.0)\end{array}$ & \\
& & $\begin{array}{l}\text { Smoking } \\
\text { method (\%) }\end{array}$ \\
& & & \\
\cline { 2 - 3 } & Rural Damascus & $\begin{array}{l}110 \\
(29.7)\end{array}$
\end{tabular}

Other

governorates

49

(13.2)

Medicine

61

(16.5)

Dentistry

$\begin{array}{ll}\mathrm{BMl}\left(\mathrm{Kg} / \mathrm{M}^{2}\right) & \leq 18.5\end{array}$

(16.7)
111

(30.0)

Hubble bubble

169

(45.7)

Electronic cigarettes

14 (3.8)

Electronic Hubble $\quad 30(8.1)$ bubble 


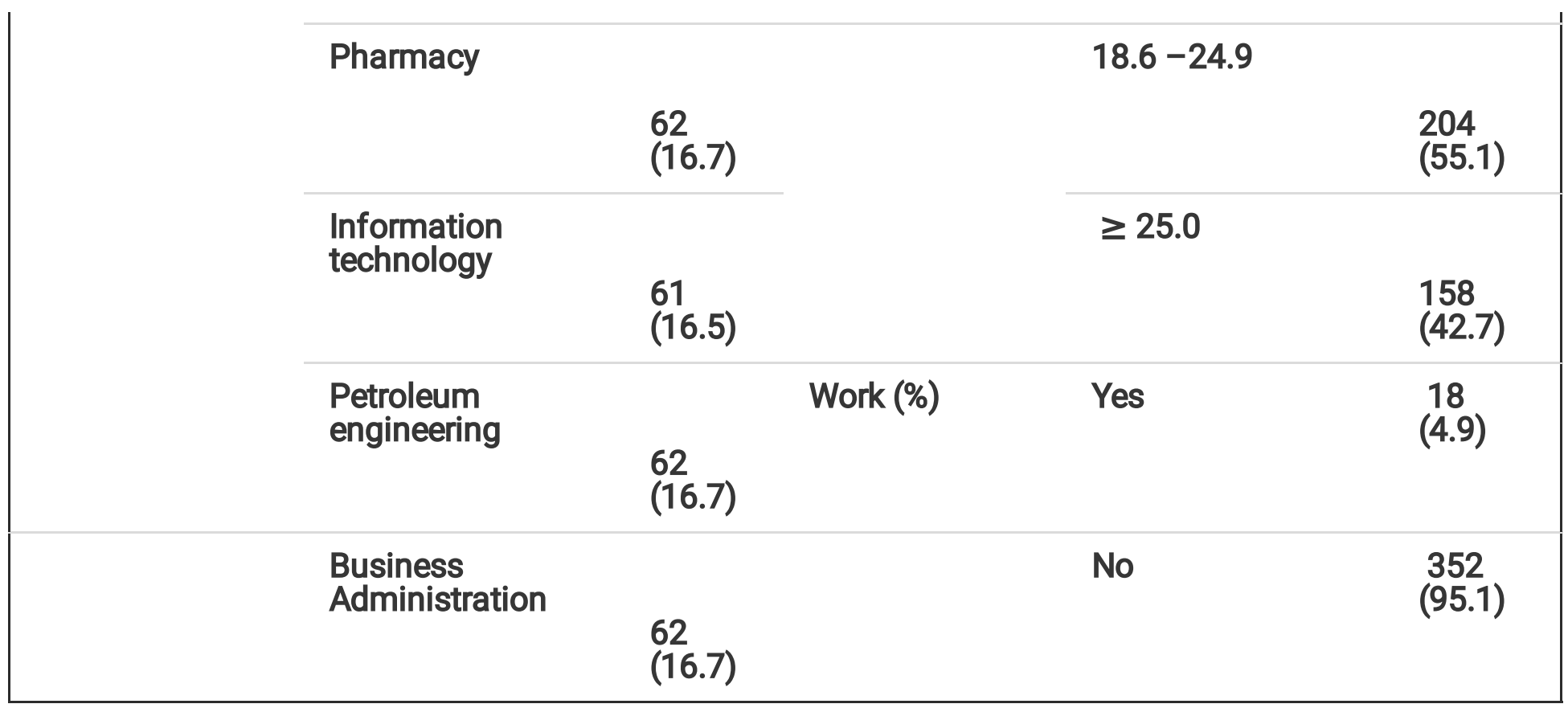

Table 2. Mini Rhinoconjunctivitis Quality of Life and Allergic Rhinitis and its Impact on Asthma Questionnaire 
Table 2. Mini Rhinoconjunctivitis Quality of Life Questionnaire: $(n=115)$

\begin{tabular}{|c|c|c|c|c|c|c|}
\hline $\begin{array}{l}\text { Not } \\
\text { troubled }\end{array}$ & $\begin{array}{l}\text { Hardly } \\
\text { troubled } \\
\text { at all }\end{array}$ & $\begin{array}{l}\text { Somewhat } \\
\text { troubled }\end{array}$ & $\begin{array}{l}\text { Moderately } \\
\text { troubled }\end{array}$ & $\begin{array}{l}\text { Quite a } \\
\text { bit } \\
\text { troubled }\end{array}$ & $\begin{array}{l}\text { Very } \\
\text { troubled }\end{array}$ & $\begin{array}{l}\text { Extremely } \\
\text { troubled }\end{array}$ \\
\hline
\end{tabular}

Activities

\begin{tabular}{|c|c|c|c|c|c|c|}
\hline $\begin{array}{l}\text { Regular } \\
\text { activities at } \\
\text { home and at } \\
\text { work (your } \\
\text { occupation } \\
\text { or tasks that } \\
\text { you have to } \\
\text { do regularly } \\
\text { around your } \\
\text { home and/or } \\
\text { garden) }\end{array}$ & $17(15)$ & $34(30)$ & $34(30)$ & $20(17)$ & $7(6)$ & $2(2)$ \\
\hline
\end{tabular}

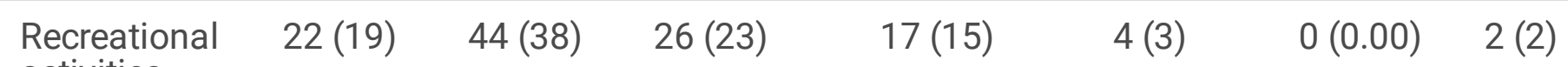
activities

(indoor and

outdoor

activities

with friends

and family,

sports,

social

activities,

and

hobbies)

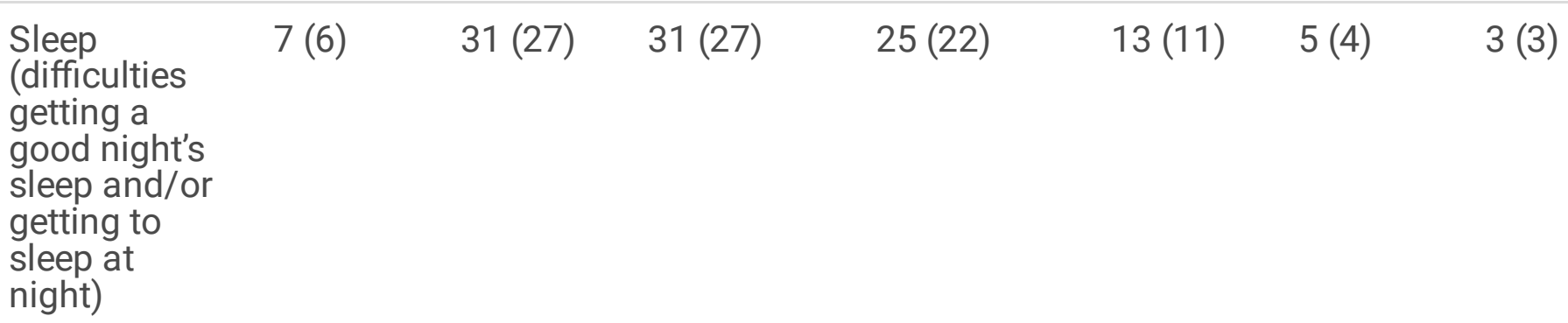

Practical Problems

\begin{tabular}{llllllll}
$\begin{array}{l}\text { Need to rub } \\
\text { nose/eyes }\end{array}$ & $7(6)$ & $22(19)$ & $42(37)$ & $24(21)$ & $12(10)$ & $4(3)$ & $4(3)$ \\
$\begin{array}{l}\text { Need to blow } \\
\text { nose } \\
\text { repeatedly }\end{array}$ & $13(11)$ & $26(23)$ & $30(26)$ & $26(23)$ & $13(11)$ & $4(3)$ & $3(3)$ \\
\hline
\end{tabular}

Nose Symptoms

$\begin{array}{llllllll}\text { Sneezing } & 9(8) & 21(18) & 37(32) & 28(24) & 9(8) & 5(4) & 6(5) \\ \begin{array}{l}\text { Stuffy } \\ \text { blocked } \\ \text { nose }\end{array} & 17(15) & 34(30) & 23(20) & 22(19) & 9(8) & 5(4) & 5(4) \\ & & & & & & & \end{array}$




\begin{tabular}{|c|c|c|c|c|c|c|c|}
\hline Runny nose & $15(13)$ & $31(27)$ & $32(28)$ & $15(13)$ & $9(8)$ & $6(5)$ & $7(6)$ \\
\hline \multicolumn{8}{|c|}{ Eye Symptoms } \\
\hline Itchy eyes & $32(28)$ & $34(30)$ & $23(20)$ & $11(10)$ & $8(7)$ & $4(3)$ & $3(3)$ \\
\hline Sore eyes & $53(46)$ & $32(28)$ & $14(12)$ & $5(4)$ & $6(5)$ & $3(3)$ & $2(2)$ \\
\hline Watery eyes & $35(30)$ & $38(33)$ & $21(18)$ & $11(10)$ & $5(4)$ & $3(3)$ & $2(2)$ \\
\hline \multicolumn{8}{|c|}{ Other Symptoms } \\
\hline $\begin{array}{l}\text { Tiredness } \\
\text { and/or } \\
\text { fatigue }\end{array}$ & $7(6)$ & $22(19)$ & $39(34)$ & $24(21)$ & $13(11)$ & $6(5)$ & $4(3)$ \\
\hline Thirst & $17(15)$ & $34(30)$ & $23(20)$ & $22(19)$ & $9(8)$ & $5(4)$ & $5(4)$ \\
\hline $\begin{array}{l}\text { Feeling } \\
\text { irritable }\end{array}$ & $17(15)$ & $29(25)$ & $27(23)$ & $22(19)$ & $14(12)$ & $2(2)$ & $4(3)$ \\
\hline \multicolumn{8}{|c|}{ Allergic Rhinitis and its Impact on Asthma: $(n=115)$} \\
\hline & \multicolumn{4}{|c|}{ Mild } & \multicolumn{3}{|c|}{ Moderate/Severe } \\
\hline \multicolumn{2}{|l|}{ Intermittent } & \multicolumn{3}{|l|}{$64(83)$} & \multicolumn{3}{|l|}{$13(17)$} \\
\hline \multicolumn{2}{|l|}{ Continuous } & \multicolumn{3}{|l|}{$27(71)$} & \multicolumn{3}{|l|}{$11(29)$} \\
\hline
\end{tabular}

Table 3. Allergic Rhinitis and its Impact on Asthma

\begin{tabular}{|lll|}
\hline \multicolumn{3}{|c|}{ Table 3. Allergic Rhinitis and its Impact on Asthma: $(\mathbf{n}=\mathbf{1 1 5})$} \\
\hline & Mild & Moderate/Severe \\
\hline Intermittent & $64(83)$ & $13(17)$ \\
\hline Continuous & $27(71)$ & $11(29)$ \\
\hline
\end{tabular}

Table 4. Activity Impairment Questionnaire plus Classroom Impairment Questions: Allergy Specific 
Table 3. Activity Impairment Questionnaire plus Classroom Impairment Questions: Allergy Specific

\begin{tabular}{lcc} 
How many hours per week do you usually attend classes? & Mean & \pm SD \\
$\begin{array}{l}\text { During the past seven days, how many hours did you miss from class because of } \\
\text { problems associated with your allergies? }\end{array}$ & 17.05 & 2.53 \\
$\begin{array}{l}\text { During the past seven days, how much did allergies affect your productivity while in } \\
\text { llass? If allergies affect your productivity in class only a little, choose a low number. } \\
\text { Choose a high number if allergies affected your productivity a great deal. }\end{array}$ & 3.72 & 2.21 \\
$\begin{array}{l}\text { During the past seven days, how much did your allergies affect your ability to do } \\
\text { your regular daily activities (work around the house, shopping, childcare, exercising, } \\
\text { and studying), other than attending classes? If allergies affected your activities only } \\
\text { a little, choose a low number. Choose a high number if allergies affected your } \\
\text { activities a great deal. }\end{array}$ & 3.20 & 2.04 \\
\hline
\end{tabular}

